\title{
Antitumorigenic Evaluation of Thalidomide Alone and in Combination with Cisplatin in DBA2/J Mice
}

\author{
Jean Marie B. Ruddy and Shyamal K. Majumdar* \\ Department of Biology, Lafayette College, Easton, PA 18042, USA
}

\begin{abstract}
Thalidomide's reported ability to inhibit angiogenesis has led to clinical trials determining its effectiveness in combating various types of cancer. This study explored thalidomide's antitumorigenic potential when administered alone and in combination with cisplatin to DBA2/J mice whose tumors were induced by murine erythroleukemic cells. Thalidomide treatment alone produced no significant inhibitory effect on tumor development and metastasis. Mice that received both drugs had significantly lower incidences of both primary and secondary tumors as compared to the untreated control group. Cisplatin, administered alone or in combination with thalidomide, led to a significant delay in tumor formation and a longer life span than was recorded in untreated mice. However, the combination treatment results were not significantly different from those of cisplatin treatment used as a single agent. In in vitro cell multiplication studies using murine erythroleukemic and murine endothelial cells, thalidomide failed to inhibit cell proliferation. However, cisplatin treatment with or without thalidomide, significantly inhibited the multiplication of both cell lines in a dose dependent manner. Thalidomide does not appear to be a beneficial adjuvant to cisplatin treatment.
\end{abstract}

\section{INTRODUCTION}

One of the most promising areas of cancer research, which was proposed by Dr Judah Folkman in 1971, involves inhibition of blood vessel growth, called angiogenesis [1]. Thalidomide, an antiangiogenic agent currently in clinical trials for an assortment of cancer treatments, was originally prescribed as a sedative in Europe in the 1950s [2]. Due to its apparent safety, the chemical was prescribed to pregnant women to relieve morning sickness. Concerns surfaced when some patients complained of tingling in their extremities characteristic of peripheral neuropathy, and thalidomide was later banned from the market when it was associated with the influx of newborns afflicted with phocomelia, a birth defect characterized by stunted limb formation [3].

Studies to identify thalidomide's teratogenic mechanism led to the discovery of its anti-inflammatory and immunomodulatory actions by facilitating the degradation of tumor necrosis factor-alpha (TNF- $\alpha$ ) mRNA in monocytes [3]. In 1998, the US Food and Drug Administration (FDA) approved marketing of thalidomide for treatment of erythema nodosum leprosum (ENL), an inflammatory condition associated with lepromatous leprosy [4]. The Celgene Corporation (Warren, NJ, USA) is the only producer of Thalomid, the commercially available form of thalidomide. Thalomid is also available off-label to combat a variety of dermatological conditions, complications of human immunodeficiency virus (HIV) infection, Crohn's disease, ulcers of the mouth and pharynx, chronic graft-versus-host disease, and rheumatoid arthritis [5].

Exploration for thalidomide's mechanism of teratogenicity has continued and Kenyon et al demonstrated that it is unrelated to the TNF- $\alpha$ mRNA degradation mentioned earlier [6]. Although its role in teratogenesis is not fully defined, thalidomide's ability to inhibit bFGF and VEGF induced angiogenesis in areas other than fetal tissue has been documented. When thalidomide's antiangiogenic capabilities were applied to cancer research in rodent models, conflicting results were obtained $[7,8,9]$. Despite the lack of conclusive results in murine models, thalidomide entered human clinical trials where inconsistent and discouraging results were produced as well. Thus far, thalidomide has been most promising in treating multiple myeloma, a cancer of the bone marrow. Due to the perplexing results of thalidomide treatment as a single agent, the focus of thalidomide research has shifted to exploring this drug's antitumorigenic abilities as an adjuvant to chemotherapy.

The efficacy of cis-dichlorodiammineplatinum (II), marketed as cisplatin, has been thoroughly studied since its introduction to cancer therapy [10]. Cisplatin has proved to be effective against solid tumors of the cervix, bladder, and prostate [11]. The cytotoxicity of cisplatin lies in its ability to form interstrand and intrastrand cross-links in DNA [10]. Prior studies have demonstrated that cisplatin is toxic to murine erythroleukemic cells (MEL), including the GM86 cell line, and cisplatin has also been identified as antimicrobial, immunosuppressive, and mutagenic $[12,13,14]$.

The purpose of this study is to evaluate the antitumorigenic activity of thalidomide, when used alone and in combination with cisplatin in DBA2/J mice whose solid tumors were induced by a subcutaneous injection of GM-86 MEL cells. The study documents primary tumor incidence, secondary tumor incidence, day of tumor detection, life span, tumor volume, and spleen enlargement. To further elucidate 
the effects of this combination drug treatment, in vitro studies were conducted utilizing the GM-86 Friend virus-induced murine erythroleukemic cell line and the SVEC4-10 murine lymph node endothelial cell line.

\section{MATERIALS AND METHODS}

\section{Cell maintenance}

Murine erythroleukemic cells have previously been shown to induce solid tumor formation at the site of a subcutaneous injection of cells [15]. These cells were derived from virally transformed erythroblasts, grow in suspension, and were purchased from the Coriell Institute for Medical Research's Cell Repository (Camden, NJ, USA). The cells were cultured in Dulbecco's Modified Eagle's Medium (Gibco BRL, Rockville, Md, USA) supplemented with 10\% fetal calf serum (DME-10) and kept in a $37^{\circ} \mathrm{C}$ incubator with $7.5 \% \mathrm{CO}_{2}$ in air.

The SVEC4-10 murine lymph node endothelial cell line is SV-40 transformed into a continuous cell line, but maintains the morphological and functional characteristics of normal endothelial cells [16]. These cells were purchased from the American Tissue Culture Collection (Rockville, Md, USA), grew as monolayer fibroblasts, and were cultured in the same conditions as stated above.

\section{Drug preparation}

Thalidomide ( $\alpha$-phthalimidoglutarimide; supplied in gratis by the Celgene Corporation, Warren, NJ, USA) is a water-insoluble white powder and was suspended in phosphate buffered saline (PBS) to a concentration of $1 \mu \mathrm{g} / \mu \mathrm{l}$ for the in vitro studies. This solution was stored at $4^{\circ} \mathrm{C}$. In the tumor development study, thalidomide was prepared on each treatment day. It was first emulsified in .1 ml Tween-80 and then suspended in PBS to reach a final concentration such that an injection of $0.2 \mathrm{ml}$ would deliver $400 \mathrm{mg} / \mathrm{kg}$, depending on the weight of the mice.

Cisplatin (Sigma-Aldrich, St Louis, Mo, USA) was dissolved in dimethyl sulfoxide (DMSO) and diluted in sterile water to a concentration of $1 \mu \mathrm{g} / \mu \mathrm{l}$. This solution was kept at $4^{\circ} \mathrm{C}$. No experimental culture contained more than $0.01 \%$ DMSO. To be administered in the in vivo study, cisplatin was dissolved in sterile water to a concentration of $1 \mu \mathrm{g} / \mu \mathrm{l}$ and again stored at $4{ }^{\circ} \mathrm{C}$. Each treatment day, this stock solution was diluted in PBS so that an injection of $0.2 \mathrm{ml}$ delivered $2.5 \mathrm{mg} / \mathrm{kg}$ or $1.5 \mathrm{mg} / \mathrm{kg}$. Again, this calculation was dependent on the weight of the mice.

\section{Mouse maintenance}

Four-week-old female DBA2/J mice were purchased from the Jackson Laboratory (Bar Harbor, Me, USA), housed six or seven to a cage, fed ad libitum, and observed daily. The cages were changed twice per week and the mice were kept in a climate-controlled room. Approval for this study was attained from the Lafayette College Institutional Animal Care and Use Committee (IACUC) and mice were handled according to those guidelines.

\section{Tumor development study}

Seven-week-old female DBA2/J mice received a subcutaneous injection of $10^{4}$ GM-86 MEL cells on the right hind leg. The cell injection day was considered day zero. Drugs were administered via intraperitoneal injections with a 25gauge syringe. Thalidomide treatment was $400 \mathrm{mg} / \mathrm{kg}$ every 48 hours beginning on day one and continuing for 15 doses $(n=16)$. Cisplatin was administered at a concentration of $1.5 \mathrm{mg} / \mathrm{kg}$ on day one, and cisplatin every 4 days for a total of 4 doses $(n=12)$. The combination treated group received both thalidomide and cisplatin in the manners explained above $(n=15)$. The untreated control group was administered both drug solvents on the same day as drug treatment $(n=18)$.

The mice were weighed once a week throughout the trial. The day of tumor detection was recorded and the dimensions of the tumors were measured every 48 hours. Tumor volume was calculated in accordance with a similar study performed by Kotoh et al [7] with the equation

$$
\text { tumor volume }=\text { length } \times \text { width }^{2} \times 0.5 \text {. }
$$

Since life span was one of the parameters considered in the study, the mice were brought to survival approximately 2 3 days before their natural death. The mice were sacrificed by cervical dislocation and the primary tumors, spleens, and secondary tumors, if present, were excised and fixed in $10 \%$ phosphate buffered formalin. The size of the spleen was also recorded at this time. The tumor development study lasted 51 days.

\section{GM-86 MEL cell multiplication study}

The cell multiplication study was conducted as described in Ruddy et al [17]. GM-86 MEL cells were seeded in $25 \mathrm{~cm}^{2}$ flasks at $10^{5}$ cells $/ \mathrm{ml}$ in $6 \mathrm{ml}$ of DME-10 and treated with thalidomide $(0,30,50$, or $100 \mu \mathrm{g} / \mathrm{ml} ; n=7)$, cisplatin $(0,0.1$, 0.5 , or $1.0 \mu \mathrm{g} / \mathrm{ml} ; n=6)$, both $(100 \mu \mathrm{g} / \mathrm{ml}$ thalidomide +0.1 , 0.5 , or $1.0 \mu \mathrm{g} / \mathrm{ml}$ cisplatin; $n=6$ ), or neither. The number of viable cells $/ \mathrm{ml}$ was counted by the Trypan blue exclusion method every 24 hours for 5 days [18].

\section{SVEC4-10 murine endothelial cell multiplication study}

Six-well plates were seeded with $5 \times 10^{4}$ SVEC4-10 cells/well in $4 \mathrm{ml}$ of DME-10, where the surface of each well was nearly $10 \mathrm{~cm}^{2}$. These cells received the same drug treatments as stated above ( $n=6$, where 2 wells composed one replicate). Because these cells grow by adhering to their substrate, $0.25 \%$ buffered trypsin (Gibco BRL, Rockville, Md, USA) was used to loosen the cells from the wells for counting by the Trypan blue exclusion method every 24 hours for 4 days.

\section{Statistical analysis}

The Prism GraphPad program was used to calculate the Student $t$ test $(P<.01)$ and 2-way Analysis of Variance (ANOVA) $(P<.01)[19]$. The $\chi^{2}$ and Fisher exact test were also utilized [20]. 
TABLE 1. Results of the tumor development study wherein DBA2/J mice received thalidomide, cisplatin, both drugs, or neither.

\begin{tabular}{|c|c|c|c|c|c|c|}
\hline & $\begin{array}{l}\text { Primary tumor } \\
\text { incidence }(\%)\end{array}$ & $\begin{array}{l}\text { Mean tumor } \\
\text { detection day } \\
\pm 1 \text { SEM }\end{array}$ & $\begin{array}{l}\text { Mean life span } \\
\pm 1 \text { SEM }\end{array}$ & $\begin{array}{l}\text { Secondary tumor } \\
\text { incidence }(\%)\end{array}$ & $\begin{array}{l}\text { Mean tumor } \\
\text { volume }\left(\mathrm{mm}^{3}\right) \\
\text { at death } \\
\pm 1 \text { SEM }\end{array}$ & $\begin{array}{l}\text { Incidence } \\
\text { of spleen } \\
\text { enlargement } \\
(\%)\end{array}$ \\
\hline $\begin{array}{l}\text { Untreated } \\
\text { control }\end{array}$ & $\begin{array}{l}17 / 18 \\
(94.4 \%)\end{array}$ & $\begin{array}{l}13.7 \pm 0.5 \\
n=17\end{array}$ & $\begin{array}{l}42.4 \pm 1.6 \\
n=17\end{array}$ & $\begin{array}{l}12 / 17 \\
(70.59 \%)\end{array}$ & $\begin{array}{l}8593.7 \pm 1207.2 \\
n=16\end{array}$ & $\begin{array}{l}9 / 17 \\
(52.94 \%)\end{array}$ \\
\hline Thalidomide & $\begin{array}{l}13 / 16 \\
(81.25 \%)\end{array}$ & $\begin{array}{l}15.7 \pm 1.9 \\
n=13\end{array}$ & $\begin{array}{l}38.9 \pm 1.7 \\
n=13\end{array}$ & $\begin{array}{l}6 / 13 \\
(46.15 \%)\end{array}$ & $\begin{array}{l}9624.2 \pm 1086.0 \\
n=13\end{array}$ & $\begin{array}{l}10 / 13 \\
(76.92 \%)\end{array}$ \\
\hline Cisplatin & $\begin{array}{l}9 / 12 \\
(75.0 \%)\end{array}$ & $\begin{array}{l}22.5 \pm 3.3^{\dagger} \\
n=8\end{array}$ & $\begin{array}{l}46.8 \pm 1.5^{\ddagger} \\
n=9\end{array}$ & $\begin{array}{l}5 / 9 \\
(55.56 \%) \\
\end{array}$ & $\begin{array}{l}7925.8 \pm 1773.9 \\
n=8\end{array}$ & $\begin{array}{l}7 / 9 \\
(77.78 \%)\end{array}$ \\
\hline $\begin{array}{l}\text { Thalidomide } \\
\text { + cisplatin }\end{array}$ & $\begin{array}{l}9 / 15^{*} \\
(60 \%)\end{array}$ & $\begin{array}{l}27.56 \pm 3.2^{\dagger \ddagger} \\
n=9\end{array}$ & $\begin{array}{l}45.8 \pm 1.5^{\ddagger} \\
n=9\end{array}$ & $\begin{array}{l}2 / 9^{*} \\
(22.22 \%)\end{array}$ & $\begin{array}{l}7305.9 \pm 1431.9 \\
n=9\end{array}$ & $\begin{array}{l}4 / 9 \\
(44.44 \%)\end{array}$ \\
\hline
\end{tabular}

* statistical difference from the untreated control group $(P \leq .05)$, as determined by the $\chi^{2}$ and Fisher exact test.

$\dagger$ statistical difference from the untreated control group $(P \leq .01)$, as determined by the Student $t$ test.

¥ statistical difference from the thalidomide treated group $(P \leq .01)$, as determined by the Student $t$ test.

\section{RESULTS}

\section{Tumor development study}

The results of the tumor development study are summarized in Table 1 . The only significant inhibition of primary or secondary tumor incidence was seen in the combination treated group, as determined by the $\chi^{2}$ and Fisher exact test. When compared to the untreated control, both cisplatin and combination treatment produced a significant delay in tumor formation, according to the Student $t$ test. Mice that received combination treatment also remained tumor-free significantly longer than those treated with only thalidomide, but no statistical difference was found between the cisplatin and combination treated mice.

The determination of mean life spans of mice in the tumor development was limited by the fact that the study was terminated at 51 days. Mice were sacrificed approximately 2 3 days from natural death via cervical dislocation, when they showed matting and thinning of the fur, a substantial tumor burden, and an overall lethargy. These parameters were constant across all treatment groups. The Student $t$ test determined that cisplatin treatment, both alone and in combination with thalidomide, significantly increased the life span of tumor-afflicted mice beyond that of the thalidomide treated mice. The difference between cisplatin and combination treatment was negligible, however.

The tumor development patterns of each treatment regimen is shown in Figure 1. The $n$ values above each bar represent the number of mice alive and afflicted with tumors at that point. The large increases in tumor volume between time points were observed among the four treatment groups. The significantly delayed tumor development of cisplatin and combination treated groups caused the tumor growth in these two groups to be offset from that of the untreated control and thalidomide treated mice by about 1 week. This is evidenced in the peak tumor volumes of the latter two groups

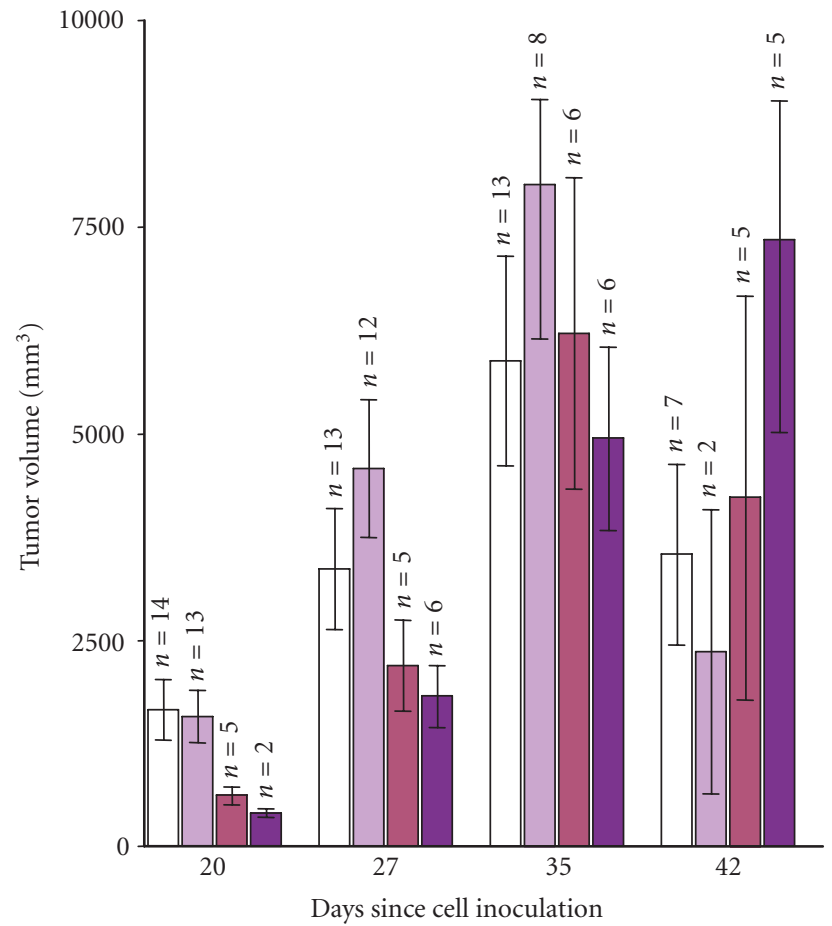

Figure 1. Mean tumor value ( $\square$ control, $\square$ thalidomide, $\square$ cisplatin, and combination) at 20,27, 35, and 42 days since tumor cell inoculation. The $n$ values vary depending on the number of surviving mice afflicted with a tumor on that day. Bars represent \pm 1 SEM.

occurring on day 35 , whereas the same climax was reached at day 42 by the combination treated mice. Upon death, the mean tumor volume was calculated for each treatment regimen, however, no statistical difference was detected between any treatment groups, according to the Student $t$ test (data not shown). 
The GM-86 MEL cell line was derived from mouse erythroblasts transformed by the Friend virus, a retrovirus known to cause splenomegaly in mice. The incidence of this spleen enlargement was documented to determine if any treatment had a therapeutic effect. The spleen was considered enlarged when it was approximately three times the size of a normal, healthy spleen. No clear trend can be discerned from the percentage of mice exhibiting spleen enlargement and none of the treatments differed significantly from the untreated control when analyzed through $\chi^{2}$ and Fisher exact tests (data not shown).

\section{GM-86 MEL cell multiplication study}

The GM-86 MEL cell multiplication data are presented as percentages of the control. 2-way ANOVA failed to find a statistically significant effect of the thalidomide treatment (see Figure 2a) on cell multiplication. Conversely, cisplatin treatment alone (see Figure $2 \mathrm{~b}$ ) and in combination with thalidomide (see Figure 2c) inhibited cell proliferation in a time and dose dependent manner. Additionally, statistical analysis of cisplatin treated versus combination treated cells indicated that the incorporation of thalidomide in the drug treatment strengthened the inhibitory effect on GM-86 MEL cell multiplication over the first 48 to 72 hours.

\section{SVEC4-10 murine endothelial cell multiplication study}

When SVEC4-10 cells received treatment with thalidomide (see Figure 3a), again, no statistically significant result was observed. Just as in the GM-86 MEL cell multiplication study, both cisplatin (see Figure 3b) and combination (see Figure 3c) drug treatment regimens resulted in time and dose dependent inhibition of cell multiplication, according to 2way ANOVA. Contrary to the relationship noted above, over the first 48 to 72 hours, statistical analysis indicated that cisplatin alone displayed a stronger inhibitory effect than combination treatment on the SVEC4-10 cells.

\section{DISCUSSION}

The concept of supplementing chemotherapy with antiangiogenic agents is aimed at improving the effect of chemotherapy without increasing the toxicity to the patient [21]. Reducing or stabilizing the vasculature of a tumor would cause the death of the cells farthest from capillaries, ultimately leading to a decreased tumor mass and an increased efficiency of administered chemotherapy drugs [21]. The angiogenesis inhibitors could also prevent regrowth and progression to metastatic disease after a chemotherapeutic regimen [21]. Unsuccessful studies utilizing thalidomide as a single agent in both mice and humans have recommended that future research be done to evaluate its efficacy as an adjuvant to chemotherapy $[22,23]$.

This study has documented the inability of thalidomide to inhibit solid tumor growth and metastasis when administered as a single agent to DBA2/J mice whose solid tumors were induced with GM-86 MEL cells. Previous studies utilizing murine breast cancer [22], melanoma [24], and colon

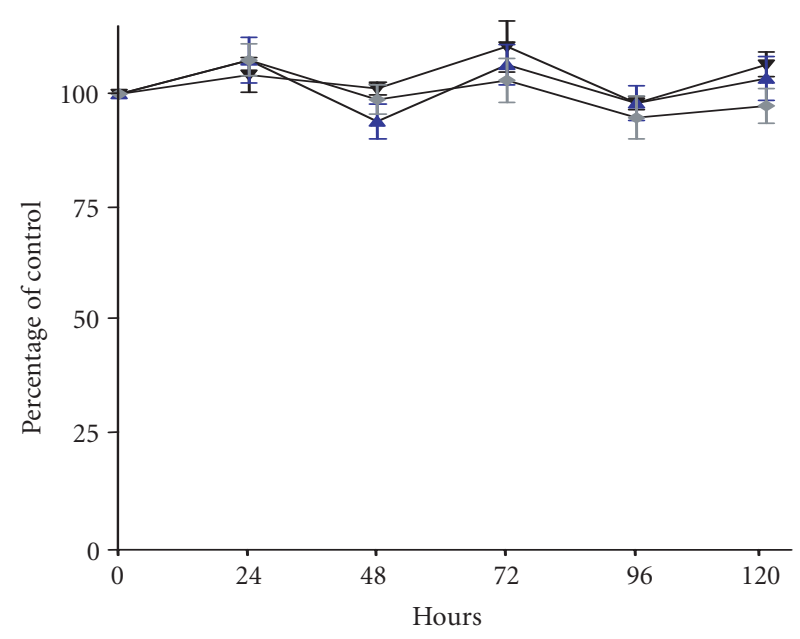

(a)

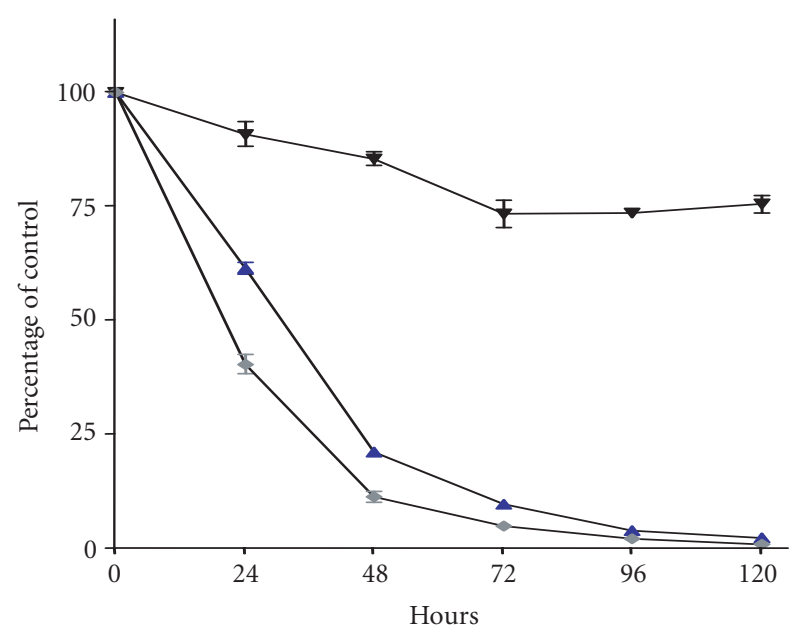

(b)

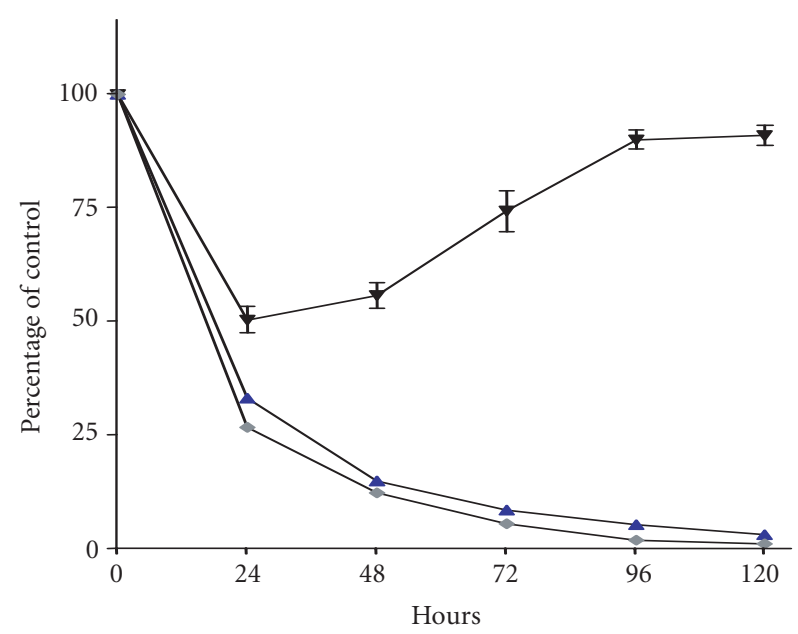

(c)

FIGURE 2. GM-86 cell multiplication after treatment with (a) thalidomide $(\diamond 100 \mu \mathrm{g} / \mathrm{ml}, \boldsymbol{\Delta} 50 \mu \mathrm{g} / \mathrm{ml}$, and $\boldsymbol{\nabla} 30 \mu \mathrm{g} / \mathrm{ml}) ;(b)$ cisplatin $(\checkmark 1.0 \mu \mathrm{g} / \mathrm{ml}, \boldsymbol{\Delta}$ $0.5 \mu \mathrm{g} / \mathrm{ml}$, and $\boldsymbol{\nabla} 0.1 \mu \mathrm{g} / \mathrm{ml}$ ); (c) both $100 \mu \mathrm{g} / \mathrm{ml}$ thalidomide and either 0.1 $(\boldsymbol{\nabla}), 0.5(\mathbf{\Delta})$, or $1.0(\diamond) \mu \mathrm{g} / \mathrm{ml}$ cisplatin. Bars represent \pm 1 SEM. 


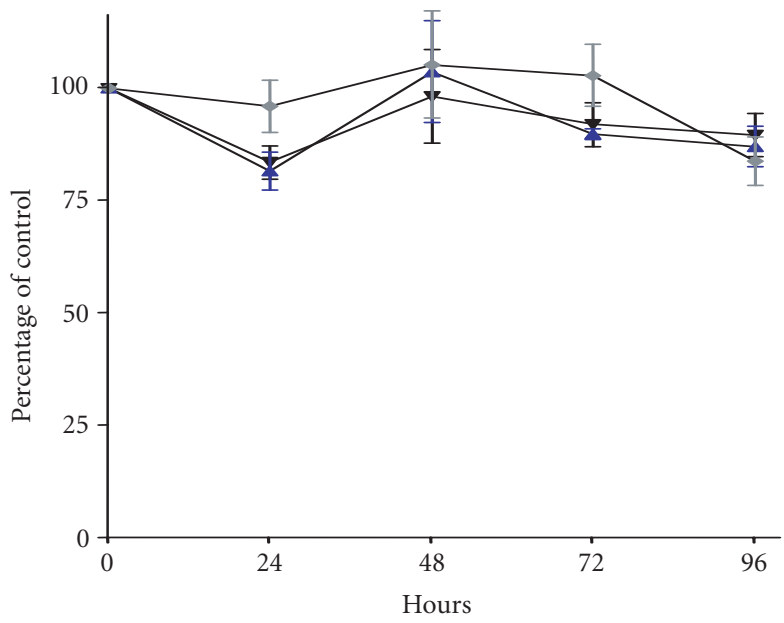

(a)

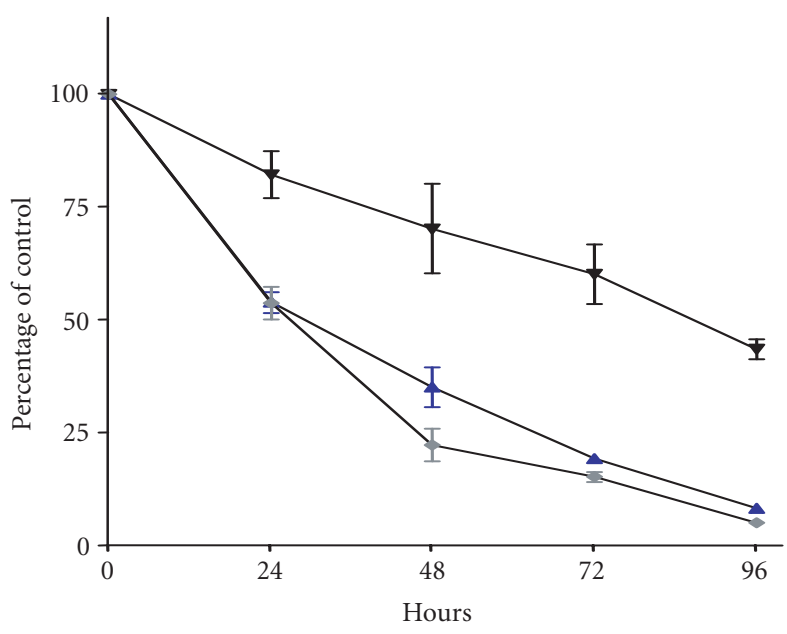

(b)

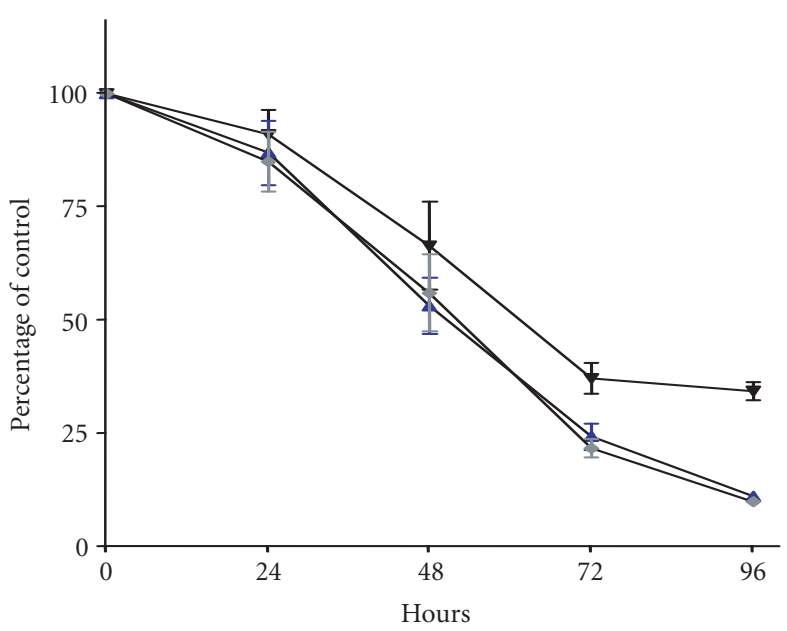

(c)

FIgURE 3. CVEC4-10 cell multiplication after treatment with (a) thalidomide $(\diamond 100 \mu \mathrm{g} / \mathrm{ml}, \boldsymbol{\Delta} 50 \mu \mathrm{g} / \mathrm{ml}$, and $\nabla 30 \mu \mathrm{g} / \mathrm{ml})$; (b) cisplatin $(\diamond 1.0 \mu \mathrm{g} / \mathrm{ml}$, $\Delta 0.5 \mu \mathrm{g} / \mathrm{ml}$, and $\boldsymbol{\nabla} 0.1 \mu \mathrm{g} / \mathrm{ml}$ ); (c) both $100 \mu \mathrm{g} / \mathrm{ml}$ thalidomide and either $0.1(\boldsymbol{\nabla}), 0.5(\boldsymbol{\Delta})$, or $1.0(\diamond) \mu \mathrm{g} / \mathrm{ml}$ cisplatin. Bars represent \pm 1 SEM. cancer [25] models recorded similar results. When murine breast cancer was treated with thalidomide and chemotherapy drugs, reduced primary and secondary tumor growth were recorded [22]. The effect of combination treatment with thalidomide and cisplatin on solid tumors induced by GM-86 MEL cells was significantly better than thalidomide alone, but no statistical analysis has shown combination therapy to be more beneficial than therapy with cisplatin as a single agent.

A previous study, which withheld treatment until tumor formation, reported that combination therapy with thalidomide and a chemotherapeutic agent was most effective when initiated before the tumor volume reached $50 \mathrm{~mm}^{3}$ [22]. Since this study began treatment 24 hours after cell inoculation, the drugs had the opportunity not only to slow tumor growth, but also to prevent it completely. The in vitro results of GM-86 MEL cells exposed to combination treatment with thalidomide and cisplatin showed an increased toxic effect over cisplatin alone. It, therefore, appears that the significant reduction in primary tumor incidence and increased delay before tumor formation seen in the combination group can be attributed to the death of some GM-86 MEL cells in the initial inoculation.

While controlling primary tumor volume is vital, the ultimate goal is to prevent metastasis. Nguyen et al, observed that once a tumor had reached $1000 \mathrm{~mm}^{3}$, it established a vascular system that allowed rapid tumor growth and progression to metastatic disease [22]. A similar growth pattern was documented in this study. While initial development may have been delayed, tumors of the cisplatin and combination treated groups were equivalent in volume to those of the untreated control and thalidomide treated mice at the time of death; but significantly more mice of the latter two groups were harboring secondary tumors. Perhaps, the decreased life spans of mice in the untreated control and thalidomide treated groups can be attributed more to the progression of metastatic disease than the volume of the primary tumors. Applying the cancer attacking strategies stated by Teicher et al, the chemotherapeutic treatment apparently lessened the cell load; and continued treatment with the antiangiogenic agent may have slowed the regrowth and metastasis such that the life span was increased [21].

Previous studies, which reported advantages to combination therapy with chemotherapeutic drugs and antiangiogenic agents, did not quantify mice life spans $[21,22]$. Because the majority of cancer treatments involve reducing tumor volume, prolonging life, and increasing quality of life, the ability of treatment regimens to increase life spans is important. Because the life spans of mice in combination treatment were not significantly longer than those of the cisplatin treated mice, there is no clear evidence that thalidomide is an effective adjuvant to cisplatin therapy.

Thalidomide's marked reduction in efficacy when used in mouse and rat models has been documented many times and referred to earlier in this paper. While continued in vivo studies may discover a particularly advantageous treatment regimen, elucidation of thalidomide's mechanism of action in human versus rodent systems will be achieved through 
in vitro studies. The primary goal of many culture investigations is to find a system in which thalidomide is effective, to isolate the active agent, and then synthesize derivatives that lack thalidomide's teratogenicity and other adverse effects.

This study appears to be the first one reporting specifically on the effect of thalidomide treatment of cultured murine endothelial cells and has documented no inhibition of cell proliferation. A previous study has documented that thalidomide had no effect on human aortic endothelial cell proliferation [26]. In a contrasting investigation, however, thalidomide did inhibit the proliferation of human umbilical vein endothelial cells in a dose dependent manner [27].

In terms of the cancerous GM-86 MEL cell line, again no inhibitory effect on cell proliferation resulted from thalidomide treatment. In vitro studies on human glioma [27], Ehrlich ascites tumor [28], and human prostate carcinoma cells [26] support this notion that thalidomide is not cytotoxic to cancer cells. Studies have suggested that thalidomide is metabolized by the cytochrome P450 isozyme [29]. In a recent study the agent was found not to increase or decrease significantly the proliferation of cultured human and murine cells in the presence or absence of human liver S9 fraction [30].

Thalidomide is reported to be an angiogenesis inhibitor; however, the exploration of this role in tumor development was not part of the present study. When administered as a single agent, thalidomide failed to inhibit tumorigenesis and metastasis in DBA2/J mice whose tumors were induced by GM-86 MEL cells. In consideration of thalidomide's potential as an adjuvant to chemotherapy, this investigation documented no advantage to combination therapy beyond that of cisplatin treatment alone. Whether thalidomide's lack of efficacy is indicative of its inability to prevent angiogenesis or the absence of the proper metabolism is an area for further study.

\section{ACKNOWLEDGMENTS}

We thank the Celgene Corporation for its generous gift of thalidomide. We would also like to thank Phil Auerbach for technical help and Andrea C. Donaghy for the preparation and proofreading of manuscript.

\section{REFERENCES}

[1] Brem S. Angiogenesis and cancer control: from concept to therapeutic trial. Cancer Control. 1999;6:436-458.

[2] Calabrese L, Fleischer AB. Thalidomide: current and potential clinical applications. Am J Med. 2000;108:487-495.

[3] Tseng S, Pak G, Washenik K, Pomeranz M, Shupack J. Rediscovering thalidomide: a review of its mechanism of action, side effects, and potential uses. J Am Acad Dermatol. 1996;35:969-979.

[4] Teo S, Morgan M, Stirling D, Thomas S. Assessment of the in vitro and in vivo genotoxicity of Thalomid ${ }^{\circledR}$ (thalidomide). Teratog Carcinog Mutagen. 2000;20:301311 .
[5] Neiger BL. The re-emergence of thalidomide: results of a scientific conference. Teratology. 2000;62:432-435.

[6] Kenyon BM, Browne F, D’Amato RJ. Effects of thalidomide and related metabolites in a mouse corneal model of neovascularization. Exp Eye Res. 1997;64:971-978.

[7] Kotoh T, Kumar D, Masunaga R, et al. Antiangiogenic therapy of human esophageal cancers with thalidomide in nude mice. Surgery. 1999;125:536-544.

[8] Gutheil J, Finucane D. Thalidomide therapy in refractory solid tumour patients. Brit J Haema. 2000;110:754.

[9] Pollard M. Thalidomide promotes metastasis of prostate adenocarcinoma cells (PA-III) in L-W rats. Cancer Lett. 1996;101:21-24.

[10] Rosenberg B. Anticancer activity of cis-dichlorodiammineplatinum (II) and some relevant chemistry. Cancer Treat Rep. 1979;63:1433-1438.

[11] Durant J. Cisplatin: a clinical overview. In: Prestayko AW, Crooke ST, Carter SK, eds. Cisplatin, Current Status and New Developments. New York, NY: Academic Press; 1980:317-321.

[12] Kang R, Baker M, Majumdar S. Cytotoxicity determination of cisplatin and carboplatin in cultured mammalian cells with the tetrazolium MTT and neutral red assays. The Nucleus. 1993;36:12-19.

[13] Rozencweig M, von Hoff D, Slavik M, Muggia FM. Cis-diamminedichloroplatinum (II): A new anticancer drug. Ann Intern Med. 1977;86:803-812.

[14] Vates TS, Brake GL, Majumdar SK, Ferguson GL. Response of murine erythroleukemia cells to cis- and trans-diamminedichloroplatinum (II). In Vitro Cell Dev Biol. 1986;22:305-310.

[15] Axelrod DE, Majumdar SK, Wivell JA, Terry RW. Tumorigenicity of Friend murine erythroleukemic cell lines differing in spontaneous differentiation rates. Int J Cancer. 1980;26:799-804.

[16] O'Connell KA, Edidin M. A mouse lymphoid endothelial cell line immortalized by simian virus 40 binds lymphocytes and retains functional characteristics of normal endothelial cells. J Immunol. 1990;144:521-525.

[17] Ruddy JM, Marc C, Majumdar SK. In vitro cytotoxic evaluation of fumagillin, a potent anti-angiogenic chemical on mouse and human cancer cell lines. Advanc Pharmacol and Toxicol. 2000;1:1-11.

[18] Freshney IR. Culture of Animal Cells: A Manual of Basic Technique. 3rd ed. New York: Wiley-Liss; 1994.

[19] GraphPad Intuitive Software for Science [computer program]. San Diego, Calif: GraphPad Software, Inc.; 1999.

[20] Gad SC, Weil CS. Statistics and Experimental Design for Toxicologists. 2nd ed. New Jersey, NJ: The Telford Press; 1988.

[21] Teicher BA, Sotomayor EA, Huang ZD. Antiangiogenic agents potentiate cytotoxic cancer therapies against primary and metastatic disease. Cancer Res. 1992;52:67026704.

[22] Nguyen M, Tran C, Barsky S, et al. Thalidomide and chemotherapy combination: preliminary results of preclinical and clinical studies. Int J Onco. 1997;10:965969. 
[23] Baidas SM, Winer EP, Fleming GF, et al. Phase II evaluation of thalidomide in patients with metastatic breast cancer. J Clin Oncol. 2000;18:2710-2717.

[24] Smith C, Friednash M, Nguyen C, et al. Failure of thalidomide as an anti-angiogenesis factor in a murine melanoma model [abstract]. J Invest Dermat. 1996;106:845.

[25] Gutman M, Szold A, Ravid A, et al. Failure of thalidomide to inhibit tumor growth and angiogenesis in vivo. Anticancer Res. 1996;16:3673-3678.

[26] Bauer KS, Dixon SC, Figg WD. Inhibition of angiogenesis by thalidomide requires metabolic activation, which is species-dependent. Biochem Pharmacol. 1998;55:1827-1834.

[27] Moreira AL, Friedlander DR, Shif B, Kaplan G, Zagzag D. Thalidomide and a thalidomide analogue inhibit endothelial cell proliferation in vitro. J Neurooncol. 1999;43:109-114.

[28] DiPaulo JA, Wenner CE. Thalidomide: effects on Ehrlich ascites tumor cells in vitro. Science. 1964;144:1583.

[29] Teo SK, Sabourin PJ, O'Brien K, Kook KA, Thomas SD. Metabolism of thalidomide in human microsomes, cloned human cytochrome P-450 isozymes, and Hansen's disease patients. J Biochem Mol Toxicol. 2000;14:140-147.

[30] Perreca SM, Ouchi K, Slotkin EM, et al. Effects of thalidomide alone and in combination with human liver S9 fraction on cell multiplication and surface ultrastructure of cultured human and murine cells. The Nucleus. 2001;44:22-27.

${ }^{*}$ Corresponding author.

E-mail: majumdas@laf ayette .edu

Fax: +1 610330 5705; Tel: +1 6103305464 

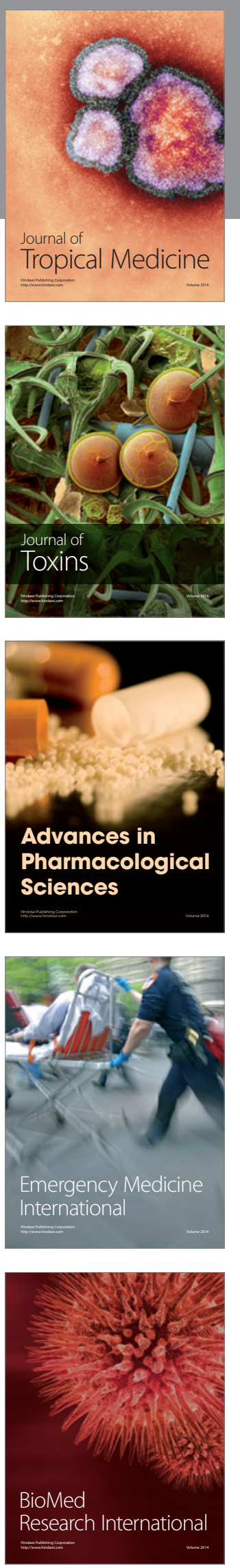
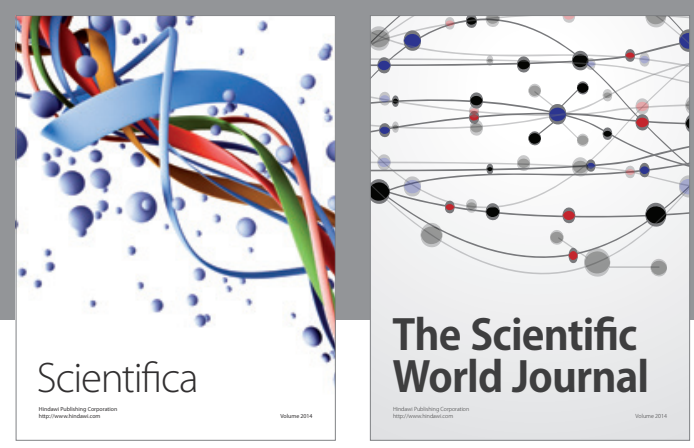

The Scientific World Journal
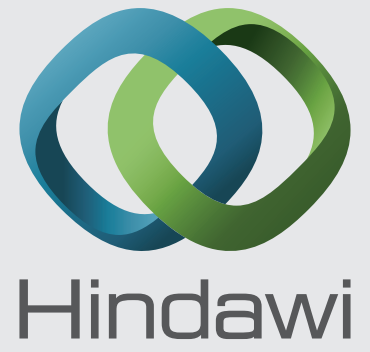

Submit your manuscripts at

http://www.hindawi.com
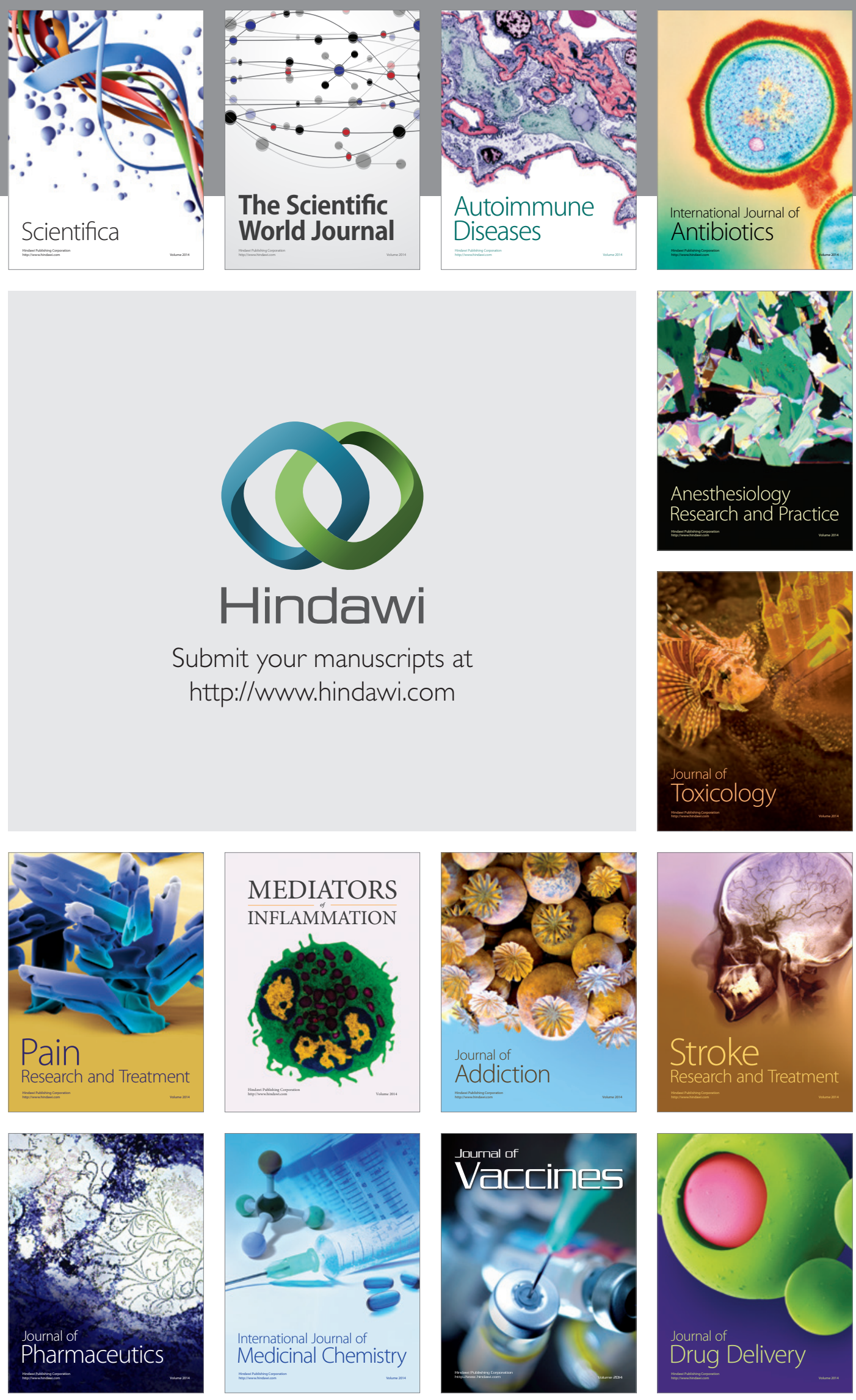